OPEN ACCESS

Edited by: Joaquin Bautista-Gallego, Instituto de la Grasa, Spain

Reviewed by: Alexandre Leclerca, Institut Pasteur, France Pedro Rodríguez-López, University of Parma, Italy

*Correspondence: Vanessa Pereira Perez Alonso vanessaperezalonso@gmail.com

Specialty section:

This article was submitted to Food Microbiology, a section of the journal

Frontiers in Microbiology

Received: 27 September 2019

Accepted: 24 January 2020

Published: 28 February 2020

Citation:

Alonso VPP, Harada AMM and Kabuki DY (2020) Competitive and/or Cooperative Interactions of Listeria monocytogenes With Bacillus cereus

in Dual-Species Biofilm Formation.

Front. Microbiol. 11:177.

doi: 10.3389/fmicb.2020.00177

\section{Competitive and/or Cooperative Interactions of Listeria monocytogenes With Bacillus cereus in Dual-Species Biofilm Formation}

\author{
Vanessa Pereira Perez Alonso*, Andréia Miho Morishita Harada and Dirce Yorika Kabuki \\ Department of Food Science, Faculty of Food Engineering, University of Campinas, Campinas, Brazil
}

Microorganisms in dairy industries can form monospecies, dual-species, or multispecies biofilms, showing cooperative or competitive behaviors, which might contribute to the reduction of efficiency of cleaning and sanitization processes and eventually turn into a potential source of contamination. This study proposes to evaluate the behavior of Listeria monocytogenes in monospecies biofilms, cocultured with Bacillus cereus. The isolates were of dairy origin, and the selection occurred after studies of competition among species. The biofilm formations on AISI 304 stainless steel at $25^{\circ} \mathrm{C}$ in a stationary culture were analyzed to observe the cooperative or competitive interactions among species, as well as the effect of pre-adhered cells. Biofilm formation assays were performed in four experiments: Experiment 1: in the presence of strains of antagonistic substance producer B. cereus (+); Experiment 2: extract of the antagonistic substance of $B$. cereus; Experiment 3: pre-adhered cells of $B$. cereus; and Experiment 4: pre-adhered cells of $L$. monocytogenes. Subsequently, cooperative behavior was observed by scanning electron microscopy. The L. monocytogenes monospecies biofilm counts of greater than 5 log colony-forming units (CFU)/ $/ \mathrm{cm}^{2}$ were also observed in dual-species biofilms in the presence of $B$. cereus (non-producers of antagonist substance), showing cooperative behavior between species. However, in the presence of antagonistic substance produced by $B$. cereus, the counts were lower, 1.39 and $1.70 \log \mathrm{CFU} / \mathrm{cm}^{2}(p>0.05)$, indicating that the antagonistic substance contributes to competitive interactions. These data are relevant for the development of new studies to control L. monocytogenes in the dairy industry.

Keywords: biofilm, dual-species biofilms, cooperative interactions, Bacillus cereus, Listeria monocytogenes

\section{INTRODUCTION}

Listeria monocytogenes and Bacillus cereus are pathogens that cause foodborne diseases and are commonly reported in the literature due the presence on environmental surfaces of dairy industries and in dairy products (Kabuki et al., 2004; Karthikeyan et al., 2015; Spanu, 2016; Saldivar et al., 2018). Chemotaxonomic markers and the analysis of $16 \mathrm{~S}$ and 23S rRNA of Listeria species 
contributed to elucidate species position in relation to other genera of Gram-positive bacteria and its close relationship and similarity to Bacillus (Sallen et al., 1996; Ryser et al., 2007). Clones of L. monocytogenes are heterogeneous and hypervirulent and can be identified by clonal complexes as CC1, CC2, CC4, and CC6, with CC1 being strongly associated with dairy products and high clinical frequency (Maury et al., 2019). Some studies consider that the high ecological diversity of the group B. cereus sensu lato is related as a single evolutionary unit defined through clonal expansion and adaptation of different hosts and environments. Nevertheless, B. cereus sensu stricto can be characterized by diarrheal type and emetic type (Fiedoruk et al., 2017; Fayad et al., 2019).

These pathogens can produce monospecies, dual-species, or multispecies biofilms on abiotic surfaces such as stainless steel (Kim et al., 2018; Silva et al., 2018; Alonso and Kabuki, 2019). In the dairy industry, 304 stainless steel is the most common and accepted alloy in the surfaces and pipelines because of the sanitary standards and requirements (Astm International, 2019; Goff, 2019). Thus, the biofilm formations may cause biocorrosion and result in the loss of millions of dollars to the industries (Palmer et al., 2015).

Biofilms are a complex form of microbial ecosystem that allows a high level of interaction among different organisms (Saxena et al., 2019; Yuan et al., 2019). These interactions can influence both the temporal and spatial properties of biofilms. One of the consequences of interspecies interactions is the ability to exhibit greater resistance to disinfectants such as ethanol, benzalkonium chloride, sodium hypochlorite, peracetic acid, and hydrogen peroxide when compared to monospecies biofilms (Yuan et al., 2019).

Behavior among species can be cooperative, competitive, or neutral (Nadell et al., 2016; Yuan et al., 2019). In the cooperative bacterial interactions, the benefit on biofilm formations occurs by facilitating adhesion, growth, and protection against biocides. Competitive interactions may occur in the dispute for space, nutrients, and energy sources (exploitative competition), or due to the production of secondary compounds such as bacteriocins, enzymes, hydrogen peroxide, and organic acids (interference competition), favoring competitive exclusion (Elias and Banin, 2012; Knight, 2015; Saxena et al., 2019; Yuan et al., 2019).

There is a great interest in the food industry on the development of new strategies and antibiofilm agents (Møretrø et al., 2019; Ripolles-Avila et al., 2019). Bacteriophages, lysozymes, bacteriocins, antimicrobial peptides, enzymes, extracellular vesicles, lytic agents, essential oils, quorum sensing inhibitors, and surface modifications are promising alternatives (Ouertani et al., 2018; Friedlander et al., 2019; Yuan et al., 2019).

Methodologies developed based on the interaction of species to eliminate or inhibit the growth of L. monocytogenes in food-processing environments (Leriche et al., 1999; Zhao et al., 2004, 2006) include the use of Listeria-specific reagents such as Listeria phages and their derivatives (endolysins, bacteriocins) (Ganegama Arachchi et al., 2013; Hagens and Loessner, 2014; Gutiérrez et al., 2016; Kim et al., 2019). A recent study showed that bacteriocin pentocin MQ1 isolated from Lactobacillus pentosus CS2 has a biopreservative potential and presented antibacterial activity against L. monocytogenes and B. cereus (Wayah and Philip, 2018). Another example is the Janthinobacterium species, which inhibit the adhesion and formation of L. monocytogenes in mixed-species biofilms, showing that antilisterial properties can impact the microbiome in food-processing facilities (Fox et al., 2014).

Several species of Bacillus species are also producers of a variety of antimicrobial compounds (peptides, lipopeptides, bacteriocins, and bacteriocin-like inhibitory substances) against bacteria and fungi (Bartel et al., 2018). In a recent study, the use of $B$. cereus (AR156) in the presence of Ralstonia solanacearum bacteria and Meloidogyne incognita nematode was effective against plant diseases (Wang et al., 2019). Another study showed that B. cereus (RC6) was capable to secrete two enzymes that degrade casein, exhibiting antimicrobial activity to B. cereus ATCC 11778 (BC45) and L. monocytogenes DISTAM MACa1 (Ouertani et al., 2018).

The aim of this work was to evaluate the interactions of $L$. monocytogenes and $B$. cereus during the biofilm formation on stainless steel at $25^{\circ} \mathrm{C}$. Understanding the competitive and/or cooperative behavior between these pathogens in dual-species biofilm is a challenge that could lead us to efficient strategies in controlling and removing biofilms (Yuan et al., 2019), contributing to a better definition of strategies in food safety (Du et al., 2018).

\section{MATERIALS AND METHODS}

\section{Bacterial Strains}

In this study, we used 5 isolated L. monocytogenes and 23 B. cereus, all of dairy origin and which were provided by the Hygiene and Legislation Laboratory culture collection (School of Food Engineering, University of Campinas). Before each experiment, the strains were frozen at $-80^{\circ} \mathrm{C}$ in $20 \%$ glycerol and inoculated separately into brain-heart infusion (BHI) broth (Difco, Sparks, MD, United States) at $35^{\circ} \mathrm{C}$ for $24 \mathrm{~h}$.

\section{Antagonist Activity of $B$. cereus Against L. monocytogenes}

We evaluated the production of antimicrobial substance for 23 isolates of $B$. cereus against 5 strains of L. monocytogenes according to the methodology used by Nascimento et al. (2009); modified methodology is reported in Supplementary Table S1. To evaluate the influence of the antimicrobial substance, the extracts of $B$. cereus were obtained. The strains were activated and inoculated separately into BHI (Difco) at $35^{\circ} \mathrm{C}$ for $24 \mathrm{~h}$. Then, $10 \mathrm{~mL}$ of the cultures was incubated in a shaker (New Brunswick Scientific, Edison, NJ, United States) at 150 revolutions/min $(\mathrm{rpm})$ at $30^{\circ} \mathrm{C}$ for $18 \mathrm{~h}$ and centrifuged at $10,000 \times g$ for $10 \mathrm{~min}$ at $4^{\circ} \mathrm{C}$ (Model RC-5C; Sorvall Instruments, Norwalk, CT, United States). The supernatant was divided into two fractions, one without $\mathrm{pH}$ adjustment (approximately 5) and the other with $\mathrm{pH}$ between 6.5 and 7.0 with $0.1 \mathrm{~N}$ sodium hydroxide $(\mathrm{NaOH})$ or $0.1 \mathrm{~N} \mathrm{HCl}$, and then sterilized by membrane filtration $0.22 \mu \mathrm{m}$ (MilliporeSigma, Burlington, MA, United States). In summary, $50 \mu \mathrm{L}$ of $B$. cereus extract was inserted into $7-\mathrm{mm}$ holes 
in BHI agar plates (0.9\% wt/vol agar) (Difco) containing $1 \%$ of L. monocytogenes culture previously grown in $\mathrm{BHI}$ broth at $35^{\circ} \mathrm{C}$ for $18 \mathrm{~h}$. Plates were incubated at $35^{\circ} \mathrm{C}$ for $24 \mathrm{~h}$, and the inhibition halos were measured. Assays were performed on duplicates in three independent experiments.

\section{Biofilm Formation of L. monocytogenes and $B$. cereus in Static Culture Surface Preparation}

Stainless-steel coupons AISI 304 were used, within the no. 4 finish standard determined by the American Society for Testing and Materials with dimensions of $10 \times 10 \times 1 \mathrm{~mm}$. The coupons were immersed in acetone for $30 \mathrm{~min}$ and in $1 \% \mathrm{NaOH}$ solution for $1 \mathrm{~h}$, consecutively. Next, they remained in $70 \%$ alcohol for $1 \mathrm{~h}$ at room temperature, rinsed in distilled water, dried at room temperature, and autoclaved at $121^{\circ} \mathrm{C}$ for $15 \mathrm{~min}$ (Parizzi et al., 2004).

\section{Inocula Preparation for Biofilm}

The strains used in the biofilm experiment were chosen after the evaluation of antagonistic activity (item 2.2). Cultures were as follows: L. monocytogenes encoded as C1-023, C1-029, E1010, B. cereus producer of antagonist substance R1-070, K1-B052, M1-012, and B. cereus non-producer of antagonist substance E1065, M1-016, M1-026. For the monospecies biofilm assays, three strains of each species [L. monocytogenes, B. cereus producer of antagonist substance $(B$. cereus +$)$, and $B$. cereus non-producer of antagonist substance $(B$. cereus -$)$ ] were activated separately in BHI broth (Difco) at $35^{\circ} \mathrm{C}$ for 18 to $24 \mathrm{~h}$. Then, $2 \mathrm{~mL}$ of each species was mixed, resulting in a pool of $6 \mathrm{~mL}$ and serially diluted in peptone water $(0.1 \% \mathrm{wt} / \mathrm{vol}$; Difco) until reaching the concentration of approximately 4 log colony-forming units $(\mathrm{CFU}) / \mathrm{mL}$. For dual-species biofilm assays, $2 \mathrm{~mL}$ of each species pool previously prepared was mixed and diluted until reaching the concentration required according to the purpose of the experiment.

\section{Dual-Species Biofilm Setup}

The observations of interactions (cooperative or competitive) were performed in four experiments on stainless-steel coupons at $25^{\circ} \mathrm{C}$ for 7 days. All experiments (1, 2, 3, and 4) were composed of three groups (Figure 1). Two independent coupons were used for each day, and all experiments were conducted in triplicates. To form the biofilm, the inoculum was added in $60 \mathrm{~mL}$ of $\mathrm{BHI}$ broth to obtain a final concentration of $3 \log \mathrm{CFU} / \mathrm{mL}$, and then the coupons were aseptically immersed.

Experiment 1. Herein, the biofilms were formed from vegetative cells, and inoculum was produced according to each group. Group 1: used as a control, formed only by L. monocytogenes biofilm; Group 2: influence of vegetative cells of $B$. cereus $(+)$ in the biofilm dual-species with $L$. monocytogenes; Group 3: biofilm dual-species in the presence B. cereus (-).

Experiment 2. The interference of the antagonist substance produced by $B$. cereus on $L$. monocytogenes monospecies biofilm formation was evaluated, adding approximately $20 \mathrm{~mL}$ of B. cereus extract in $40 \mathrm{~mL} \mathrm{BHI}$ broth. Group 1: L. monocytogenes biofilm (control group); Group 2: herein, $20 \mathrm{~mL}$ of B. cereus (+) extract was used on L. monocytogenes biofilm; Group 3: $20 \mathrm{~mL}$ of $B$. cereus (-) extract was used on $L$. monocytogenes biofilm.

Experiment 3. The behavior of pre-adhered B. cereus cells on stainless steel on L. monocytogenes biofilm was assessed. For the adhesion of vegetative cells, the coupons were immersed in BHI broth containing $5 \log \mathrm{CFU} / \mathrm{mL}$ of inoculum at $25^{\circ} \mathrm{C}$ for $6 \mathrm{~h}$ until approximately $3 \log \mathrm{CFU} / \mathrm{cm}^{2}$, and then rinsed in $10 \mathrm{~mL}$ peptone water $(0.1 \% \mathrm{wt} / \mathrm{vol})$. Group 1: L. monocytogenes biofilm (control group); Group 2: pre-adhered B. cereus $(+)$ on coupons immersed in L. monocytogenes inoculum; Group 3: pre-adhered $B$. cereus (-) immersed in L. monocytogenes inoculum.

Experiment 4. Pre-adhered L. monocytogenes was carried out by the same procedure as Experiment 3. Group 1: L. monocytogenes biofilm (control group); Group 2: coupons with pre-adhered L. monocytogenes immersed in B. cereus (+) inoculum; Group 3: pre-adhered L. monocytogenes on coupons immersed in B. cereus $(-)$ inoculum.

Substrate exchange (BHI) occurred on the second and fourth days for all experiments, but for Experiment 2, the antagonist substance was not added again.

\section{Count of $L$. monocytogenes and $B$. cereus on Stainless-Steel Coupons}

In the days of incubation (1, 2, 4, and 7), two coupons of each group were removed from the culture medium and evaluated. Coupons were immersed separately in $10 \mathrm{~mL}$ peptone solution $(0.1 \% \mathrm{wt} / \mathrm{vol})$ for $1 \mathrm{~min}$ to remove the planktonic cells. Then, coupons were transferred to $5 \mathrm{~mL}$ saline solution $(0.85 \%$ $\mathrm{NaCl} \mathrm{wt/vol})$ and vortexed $(2800 \mathrm{rpm})$ for $2 \mathrm{~min}$ to remove the sessile cells (Andrade et al., 1998). The suspensions were diluted and spread plated on BHI agar and MYP (mannitolegg yolk-polymyxin) for the enumeration of $L$. monocytogenes and $B$. cereus, respectively. The colonies of L. monocytogenes on BHI agar were differentiated by size and morphological characteristics. The plates were incubated at $35^{\circ} \mathrm{C}$ for $48 \mathrm{~h}$. Then, the colonies were counted, and the results expressed as $\log \mathrm{CFU} / \mathrm{cm}^{2}$.

\section{Statistical Analysis}

Variables related to biofilm formation and the interactions of species were evaluated by analysis of variance, and differences were compared using the Tukey test at 5\% significance level, using the software Statistic version 8.0 (StatSoft, Tulsa, OK, United States).

\section{Scanning Electron Microscopy}

Coupons were analyzed by scanning electron microscopy (SEM) according to the protocol proposed by Lou et al. (2013).

The coupons were immersed in peptone water $(0.1 \% \mathrm{wt} / \mathrm{vol})$ for removal of non-adhered cells. To fix the biofilm, $2 \mathrm{~mL}$ of 0.1 $\mathrm{M}$ phosphate-buffered solution (Sigma-Aldrich, St. Louis, MO, United States), supplemented with $2 \%$ (wt/vol) glutaraldehyde (Sigma-Aldrich), was used. Samples were rinsed in $0.1 \mathrm{M}$ phosphate-buffered solution, followed by dehydration with ethanol P.A. (Merck SA Chemical Industries, Rio de Janeiro, Brazil) at increasing concentrations (30, 50, 70, 80, and 95\%) and three times in ethanol $100 \%$ for $10 \mathrm{~min}$. Then, these 


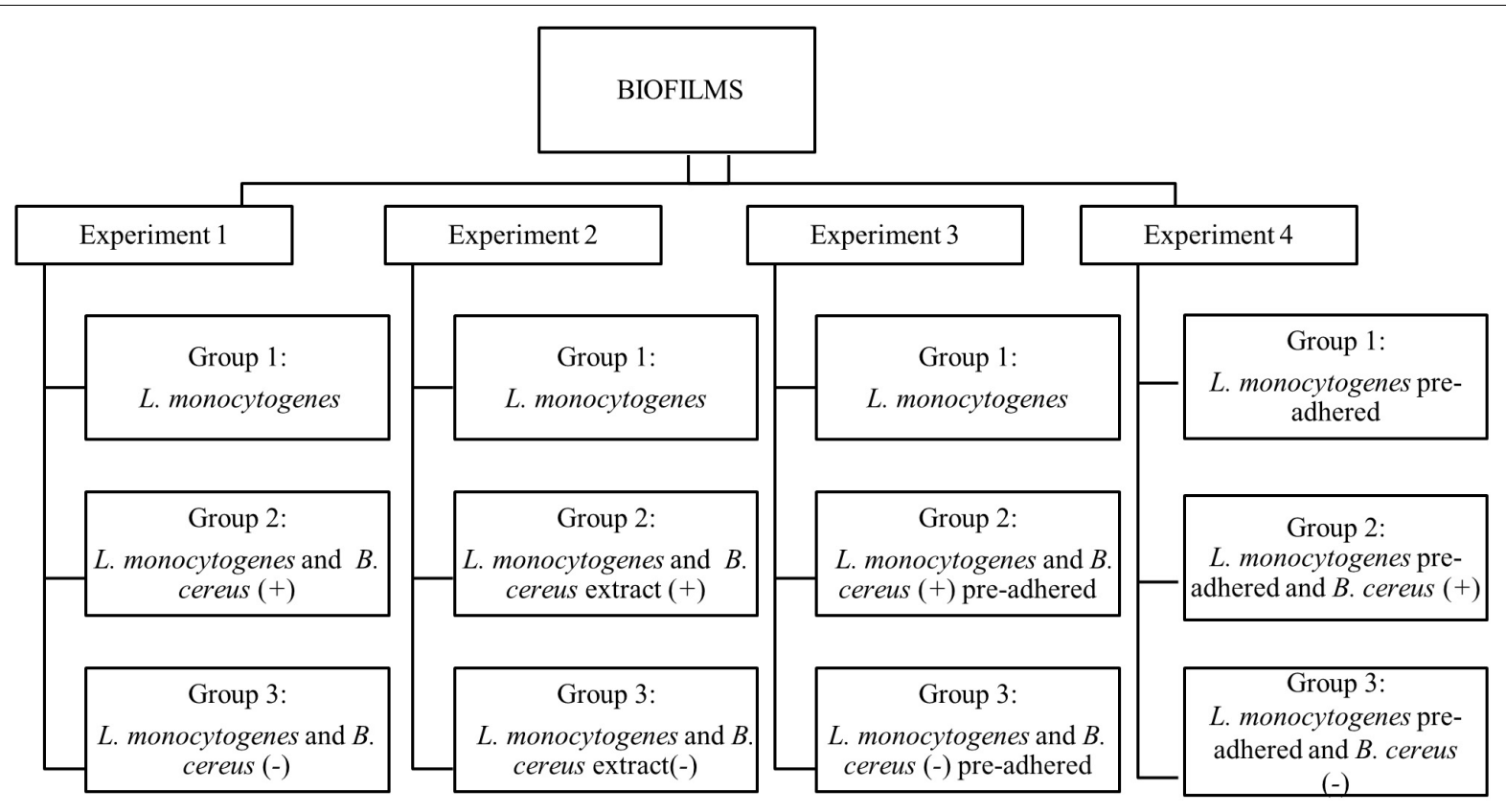

FIGURE 1 | Flowchart of dual-species biofilm formation in stationary culture on stainless steel surface in BHI kept at $25^{\circ} \mathrm{C}$. B. cereus producer of antagonist substance (+) and B. cereus non-producer antagonist substances (-).

were transferred to the critical point dryer (model CPD 030; Balzers, Liechtenstein) using $\mathrm{CO}^{2}$ for complete removal of ethanol. After drying, the coupons were coated with a metal layer in the apparatus "Sputter Coater" (model SCD 050; Balzers, Liechtenstein) and analyzed by SEM (model JSM 5800LV; JEOL, Tokyo, Japan; and Phenom-FEI Company, Hillsboro, OR, United States) (Lou et al., 2013).

The images obtained by SEM were analyzed by ImageJ version 1.52N (National Institutes of Health, Bethesda, MD, United States).

\section{RESULTS AND DISCUSSION}

\section{Evaluation of Antagonistic Activity of $B$. cereus Against $L$. monocytogenes}

Three of 23 B. cereus cultures showed activity $>2.0-\mathrm{cm}$ diameter of inhibition zone, thus considered strong producers of antagonistic substances: R1-070, K1-B052, and M1-012. This result evidences a low occurrence $(13 \%)$ of $B$. cereus capable of producing an antimicrobial substance in dairy products. The inhibition halos varied from 2 to $12 \mathrm{~mm}$ (Table 1). Culture of B. cereus M1-012, isolated from pâté cheese, showed the highest inhibitory effect (12 mm).

Other studies demonstrated the effectiveness of Bacillus species against fungal pathogens in corn (Fusarium verticillioides) (Douriet-Gámez et al., 2018), bacteria ( $R$. solanacearum), and nematodes ( $M$. incognita) disease in tomato (Wang et al., 2019). Peptides and bacteriocins produced by this species may also inhibit L. monocytogenes, Bacillus subtilis, Escherichia coli, and Salmonella enteritidis, Salmonella typhi, and Staphylococcus aureus (Bizani et al., 2005; Yusra and Novelina, 2014). These observations are important on the development of solutions to eliminate biofilms in the food industry (Liu et al., 2016; Ouertani et al., 2018).

\section{Monospecies Biofilm Formation of L. monocytogenes}

All the experiments of monospecies biofilms (Group 1) were used as control for comparison with the other assays reported in this study (Figure 1). L. monocytogenes formed monospecies biofilm in Experiments 1 and 2 on the second sampling day (Figures 2A,B) and in Experiments 3 and 4 on the first day. In Experiment 4, there was a modification in the control group:

TABLE 1 | Diameters average of inhibition halos of Listeria monocytogenes strains by Bacillus cereus.

\begin{tabular}{|c|c|c|c|c|c|c|}
\hline \multirow{2}{*}{$\frac{\text { B. cereus }}{\text { Identification }}$} & \multicolumn{6}{|c|}{ L. monocytogenes } \\
\hline & $\mathrm{C} 1-023(\mathrm{~mm})$ & SD & C1-029 (mm) & SD & $\mathrm{E} 1-010(\mathrm{~mm})$ & SD \\
\hline R1-070 & 4 & \pm 0.23 & 4 & \pm 0.23 & 2 & \pm 0.12 \\
\hline $\mathrm{R} 1-070^{*}$ & 8 & \pm 0.20 & 10 & \pm 0.31 & 6 & \pm 0.20 \\
\hline K1-B052 & 4 & \pm 0.31 & 4 & \pm 0.23 & 2 & \pm 0.12 \\
\hline K1-B052* & 8 & \pm 0.31 & 10 & \pm 0.20 & 6 & \pm 0.20 \\
\hline M1-012 & 10 & \pm 0.23 & 10 & \pm 0.12 & 8 & \pm 0.31 \\
\hline M1-012* & 12 & \pm 0.35 & 12 & \pm 0.42 & 10 & \pm 0.20 \\
\hline
\end{tabular}

*With $\mathrm{pH}$ adjustment (6.5-7.0). SD: \pm standard deviation. Origin of the strains: B. cereus R1-070 (Minas Frescal Cheese), K1-B052 (Minas Frescal Cheese), and M1-012 (Ricotta Pâté) and L. monocytogenes C1-023 (Minas Frescal Cheese), C1-029 (Coalho Cheese), and E1-010 (Ricotta). 

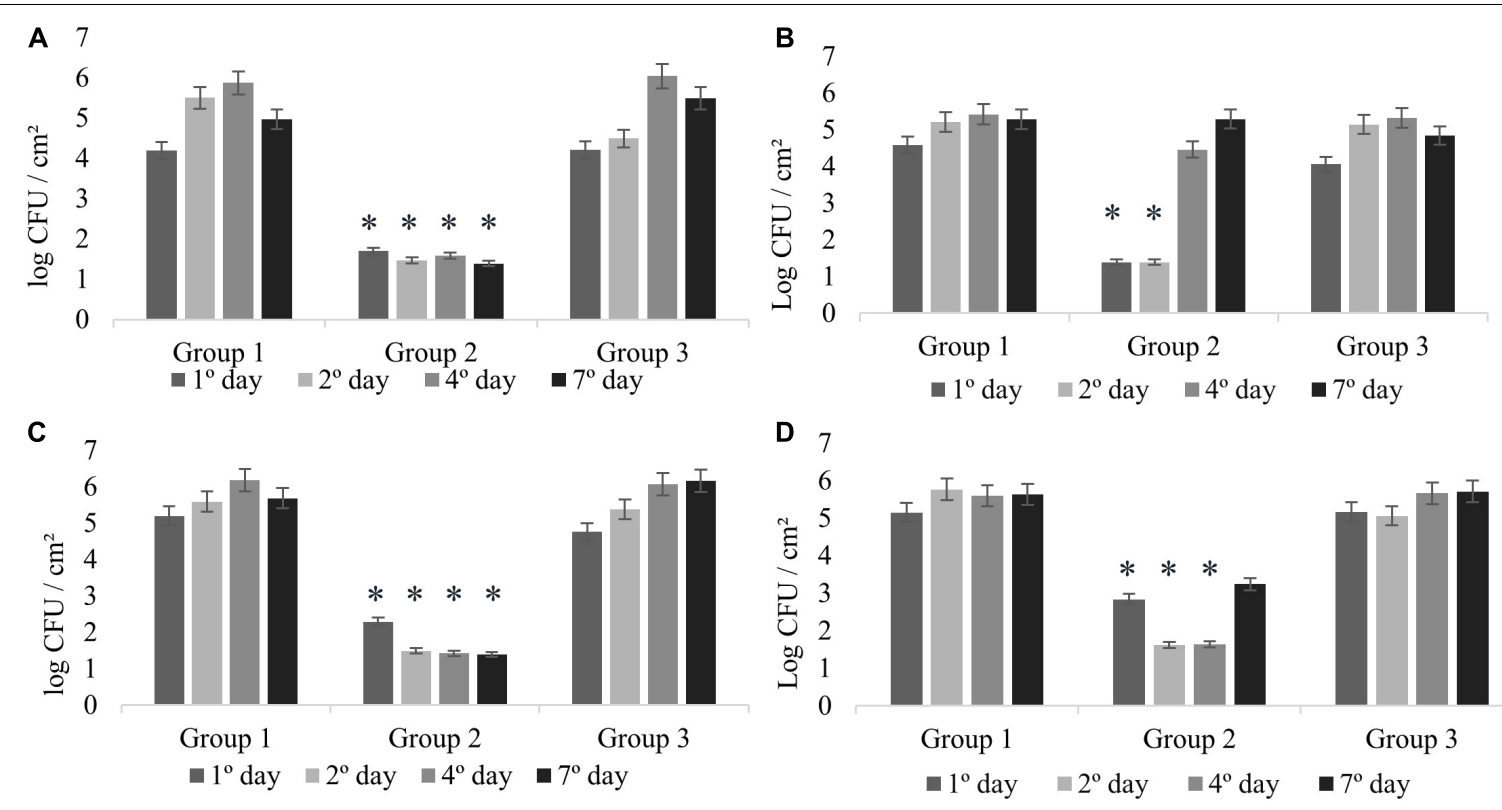

FIGURE 2 | Counts of $L$. monocytogenes at $25^{\circ} \mathrm{C}$ expressed in log CFU/cm². Experiment 1 (A) in presence of $B$. cereus producer and non-producer of antagonistic substance; Experiment 2 (B) in presence of antimicrobial extract; Experiment 3 (C) in presence of B. cereus pre-adhered; and Experiment 4 (D) in presence of L. monocytogenes pre-adhered. * $p<0.05$.

the biofilm was made after pre-adherence of L. monocytogenes in order to check for possible interference in the biofilm formation. Despite that, when compared to the other experiments, there were no differences $(p>0.05)$.

In agreement with previous studies, L. monocytogenes isolated from milk and dairy products are able to form monospecies biofilm (Alonso and Kabuki, 2019; Skowron et al., 2019). Agglomerates with counts greater than $5 \mathrm{log} \mathrm{CFU} / \mathrm{cm}^{2}$ were considered biofilms in a maturity stage because this threshold demonstrates that bacteria reached the three-dimensional complexity in their structure surrounded by extracellular polymeric substances (EPS) (Ronner and Wong, 1993).

\section{Experiment 1: Dual-Species Biofilm Formation of $L$. monocytogenes and B. cereus}

The interactions in dual-species biofilms (Experiment 1) were analyzed in the presence of $B$. cereus producer of antagonistic substance (+) (Group 2) and B. cereus nonproducer of antagonistic substance $(-)$ (Group 3). In Group 2, L. monocytogenes showed adherence on stainless steel with counts between 1.70 and $1.39 \log \mathrm{CFU} / \mathrm{cm}^{2}$ (Figure 2A), which is not considered biofilm formation (Ronner and Wong, 1993). Therefore, the interaction for this group can be considered as competitive, in which the antagonistic substance inhibited the biofilm formation of L. monocytogenes, showing antagonistic interactions among both species. On the other hand, the results of Group 3 revealed cooperative interactions with a statistically significant difference $(p<0.05)$ presenting counts between 6.04 and $5.49 \log \mathrm{CFU} / \mathrm{cm}^{2}$ (Figure 2A), as evidenced by the control group (between 5.50 and $5.87 \log \mathrm{CFU} / \mathrm{cm}^{2}$ ) (Figure 2A). These results demonstrate that the bacterial diversity present in foods may behave differently, thus enabling competitive or cooperative interactions, further corroborating with other studies (Fox et al., 2014).

Interactions among species have an important purpose in the formation, structure, and function of bacterial communities (Liu et al., 2017). According to the literature, other species are also capable of inhibiting the growth of Listeria, for example, Pseudomonas graminis CPA-7, Lactobacillus plantarum Tennozu-SU2, and Lactococcus lactis subsp. lactis BF1 (Collazo et al., 2019; Haraguchi et al., 2019). Some studies reported the opposite results in dual-species biofilms, such as Flavobacterium species and Pseudomonas, known for increasing attachment of L. monocytogenes (Sasahara and Zottola, 1993; Bremer et al., 2001). This behavior is due to the protection of the species among themselves or to the induction of specific tolerance phenotypes as a response to competitors (Parijs and Steenackers, 2018). Interactions in biofilms may also be associated with the acquisition of conjugation genes due to lateral gene transfer (Saraoui et al., 2016). Usually, strains that improve colonization and biofilm formation contribute to the persistence of L. monocytogenes in food industry plants and are a potential risk to food safety (Giaouris et al., 2015).

\section{Experiment 2: Effect of the B. cereus Extract in Biofilm Formation of L. monocytogenes}

In this experiment, the possible effects of antagonist substance produced by B. cereus (Group 2) on L. monocytogenes 
biofilm formation were verified, comparing with the non-antagonistic substance producer strains (Group 3). The counts of L. monocytogenes for Group 2 on the first and second days were less than $1.39 \log \mathrm{CFU} / \mathrm{cm}^{2}$ (Figure 2B), evidencing the antibiofilm activity of the antagonistic substance, whereas in the control group, biofilm formation was $5.21 \log \mathrm{CFU} / \mathrm{cm}^{2}$ (Figure 2B). This result is in agreement with that obtained in the antagonistic competition between individual species (see section "Experiment 1: Dual-Species Biofilm Formation of L. monocytogenes and B. cereus").

There was a difference in L. monocytogenes counting $(p<0.05)$ of approximately 3 and 4 logarithmic cycles between Group 2 and Group 3 results (Figures 2B,C). After the second day, the culture medium (BHI) was changed; however, the substance was not replaced, so that we could observe how L. monocytogenes would behave after interference. Counts reached 4.46 and 5.29 $\log \mathrm{CFU} / \mathrm{cm}^{2}$ at fourth and seventh days, respectively.

The behavior was similar for Experiments 1 and 2 (Figures 2A,B), indicating the antibiofilm activity of $B$. cereus against L. monocytogenes. The inhibition observed in Experiment 1 might be related to interference competition rather than exploitative competition, due to the production of secondary compounds or antimicrobial agents that facilitate competitor dispersal (Ouertani et al., 2018; Yuan et al., 2019). Antagonistic response depends on several factors, such as strain-specific response, substrates, and the interaction between species (Bartel et al., 2018). In general, the antagonistic assays can offer an alternative to the indiscriminate use of chemicals, and therefore it has attracted increasing interest from researchers (Liu et al., 2017; Bartel et al., 2018).

\section{Experiments 3 and 4: Effect of Pre-adhered Cells in Dual-Species Biofilm Formation}

Pre-adhered cells of $B$. cereus and L. monocytogenes on coupons were used to evaluate the possible change of behavior in the species in relation to the inhibitory effect. Eventual increase or reduction was compared with Experiments 3 and 4 (Figures 2C,D) and also with Experiment 1, when species were inserted simultaneously.

In Experiments 3 and 4, competitive interactions were observed in Group 2, confirming the result found in Experiment 1. In these groups, the counts were between less than 1.39 to $2.29 \log \mathrm{CFU} / \mathrm{cm}^{2}$ (Experiment 3) and 1.62 to $3.24 \mathrm{log} \mathrm{CFU} / \mathrm{cm}^{2}$ (Experiment 4). Although L. monocytogenes cells adhered, the count did not reach the minimum value to be considered biofilm (5 $\log \mathrm{CFU} / \mathrm{cm}^{2}$ ) (Ronner and Wong, 1993). This behavior confirms that the presence of antagonistic substance reduces competition and affects the prevalence of some species (Parijs and Steenackers, 2018).

In Group 3, in the presence of pre-adhered B. cereus (-) (Experiment 3; Figure 2C) and pre-adhered L. monocytogenes (Experiment 4; Figure 2D), we observed the cooperative interaction. The counts were similar to those of Group 1, varying between 4.76 and $6.16 \log \mathrm{CFU} / \mathrm{cm}^{2}$ (Experiment 3) and between 5.16 and $5.71 \log \mathrm{CFU} / \mathrm{cm}^{2}$ (Experiment 4).

In dual-species biofilm, the difficulty of L. monocytogenes to form biofilms can be affected by physicochemical characteristics of contact surfaces and the hydrophilic properties of strains (Giovannacci et al., 2000), showing greater difficulty to interact with the stainless-steel surface, also considered hydrophilic (Bos et al., 2000). On the other hand, the cells of B. cereus exhibit hydrophobic properties, facilitating the interaction with stainless steel (hydrophilic) (Bos et al., 2000). Therefore, hydrophobicity is also correlated with aggregation of cells (Park-ji et al., 2019).

The inhibition of some multispecies biofilm could be due to the quorum sensing system, production of antibacterial substances (Jahid et al., 2019), and the presence of organic compounds, such as dairy substrates, which may lead to dispersion by seeding (Alonso and Kabuki, 2019; Jahid et al., 2019).

These results contribute to the knowledge on the behavior of bacterial strain interactions in dual-species biofilm, showing that interactions can contribute to competition and cooperation, increasing antimicrobial tolerance (Parijs and Steenackers, 2018).

\section{Structure of Dual-Species Biofilms in SEM}

The specific spatial arrangement of the dual-species biofilm was observed by SEM for Experiment 1-Group 3 on the fourth day at $25^{\circ} \mathrm{C}$. The cooperative interaction in dual-species biofilms between L. monocytogenes (Figure 3B) and B. cereus (Figure 3C) was easily visualized in microscopy (Figures 3,4) due to the formation of multilayer cells (Kalmokoff et al., 2001). The size of cells and bacterial agglomerates on stainless steel was analyzed by Image J software.

In the cell size analysis, $n=3$ were measured. We observed that $B$. cereus cells presented lengths ranging from 2.23 to $6.92 \pm 0.75 \mu \mathrm{m}$ and diameters from 1.00 to $1.33 \pm 0.07 \mu \mathrm{m}$, whereas L. monocytogenes were measured with lengths from 1.08 to $1.55 \pm 0.07$ and 0.46 to $0.70 \pm 0.05 \mu \mathrm{m}$ in diameter.

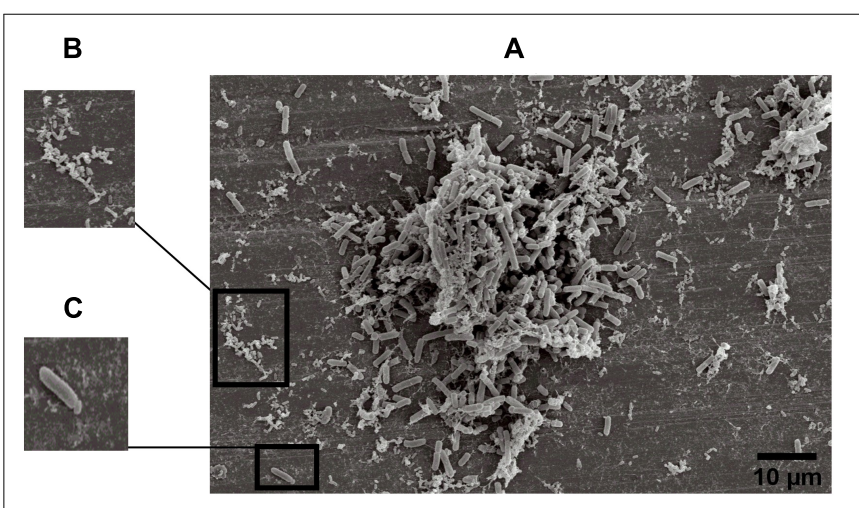

FIGURE 3 | Image obtained by SEM (JEOL) of microbial cooperative interaction of $L$. monocytogenes and B. cereus (+). Experiment 1, Group 3, on stainless steel (A); L. monocytogenes (B); and B. cereus (C). 

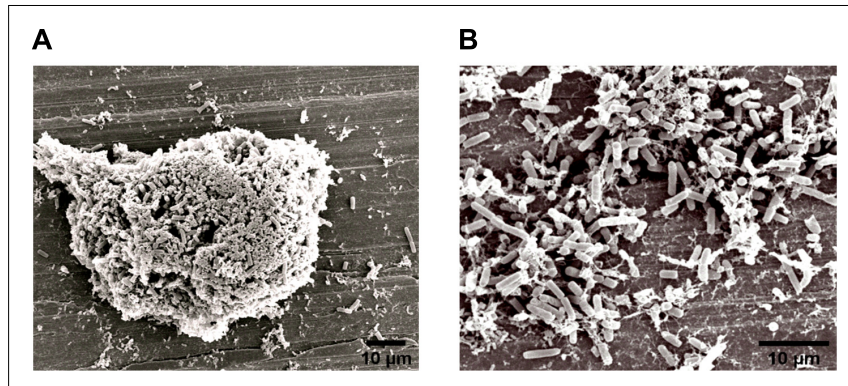

c

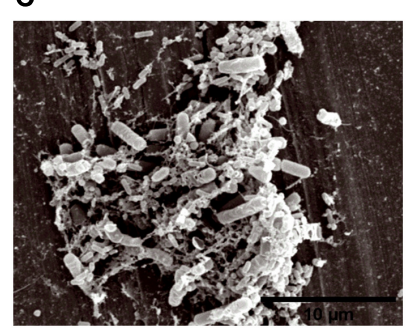

D

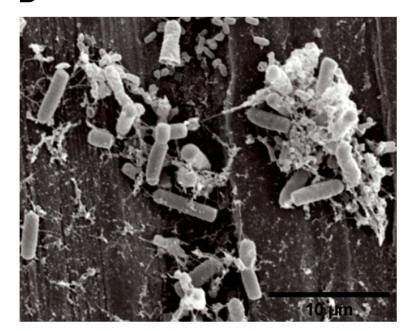

FIGURE 4 | Image obtained by SEM (JEOL) of the interaction between L. monocytogenes and B. cereus in the biofilm on stainless steel (Experiment 1, Group 3). Agglomerates of dual-species biofilms (A); Biofilm cells (B,C); and low EPS production (D).
The EPS provides protection and trap nutrients for microorganisms in the biofilm, contributing to the formation of the cluster (Figure 4A). However, the adhesion of bacteria on surfaces is not related to the production of EPS, because adhesion and consequent biofilm formation can occur even in the absence of the polymeric substance (Hoodt and Zottola, 1997). Despite lack of information on the molecular mechanisms, such as genes and EPS characteristics involved in biofilm formation (Park-ji et al., 2019), there are reports in the literature that EPS production depends on stress and environmental conditions (Giaouris et al., 2015).

The adhesion of $B$. cereus to surfaces also contributes to the formation of a conditioning layer, facilitating subsequent adhesion of other bacteria (Marchand et al., 2012), and the capability to form biofilms under static conditions (Wijman et al., 2007), because of their hydrophobic properties (Park-ji et al., 2019).

Herald and Zottola (1988) and Hoodt and Zottola (1997) found that Listeria species and Yersinia species showed an increased adhesion capacity during high metabolic activity. Thus, it is also possible that in our experiments the microorganisms were in this phase at the fourth day of incubation, facilitating the visualization of the species on the stainless steel in Group 3 (Figures 3, 4).

\section{CONCLUSION}

According to the SEM measurements, the area of the formed aggregates showed values between 1616.7 and 33,199.7 $\mu^{2}$ (Supplementary Figure S1). Although elongated cells have been reported in biofilms of other species (Janissen et al., 2015), in this experiment both species (B. cereus and L. monocytogenes) had the common planktonic cell size (Logan and De Vos, 2015; Ludwig et al., 2015).

Three types of bacterial organization are known in biofilms: microcolonies, forming separate small niches side by side (Nielsen et al., 2000); layered structures, where each species is located in a different layer (Habimana et al., 2010); and niches with mixed species (Liu et al., 2018). In SEM experiment, the formation of niches with mixed species was observed, as shown in Figures 3, 4 in which microorganisms coexist in dualspecies biofilms incorporated with EPS matrix (Liu et al., 2018; Yuan et al., 2019).

The organization of the biofilm structure is not random and might favor the survival of present species, which reveals the relevance of the interactive nature between them. These organizations allow both competitive and cooperative interactions (An et al., 2006; Habimana et al., 2010) influencing the survival rate of species in unfavorable environments (Nadell et al., 2016).

In dual-species biofilms, a small amount of EPS was observed by the microscope (Figures 3, 4). This may possibly be justified by the presence of $L$. monocytogenes, because it is often reported as a few EPS producers (Doijad et al., 2015) compared to B. cereus (Park-ji et al., 2019). However, this small amount is sufficient for both species to survive in the biofilm (Park-ji et al., 2019).
The L. monocytogenes strains isolated from dairy products showed the capacity of cooperative and competitive interactions in dual-species biofilm with $B$. cereus. Cooperative interaction in mixed species showed that bacterial spatial organization coexists in the same matrix incorporated with EPS, corroborated by SEM measurements. Moreover, competitive interaction was dependent on the ability of $B$. cereus to produce metabolites that showed antibiofilm action against L. monocytogenes. Specific and in-depth studies on the biochemical characterization of antimicrobial substances produced by $B$. cereus may be the subject of further research.

\section{DATA AVAILABILITY STATEMENT}

The raw data supporting the conclusions of this manuscript will be made available by the authors, without undue reservation, to any qualified researcher.

\section{AUTHOR CONTRIBUTIONS}

VA and AH performed the experimental stages, the statistical analyzes, and wrote the manuscript. VA wrote, adapted to the guidelines, reviewed, and finalized the manuscript. DK provided and designed the experiments, supervised all the steps, and reviewed the manuscript. 


\section{FUNDING}

This work was financially supported by the Coordenação de Aperfeiçoamento de Pessoal de Nível Superior - Brazil (CAPES) - Finance Code 001.

\section{ACKNOWLEDGMENTS}

$\mathrm{AH}$ is grateful to the National Council for Scientific and Technological Development $(\mathrm{CNPq})$ for granting the

\section{REFERENCES}

Alonso, V. P. P., and Kabuki, D. Y. (2019). Formation and dispersal of biofilms in dairy substrates. Int. J. Dairy Technol. 72, 472-478. doi: 10.1111/1471-0307. 12587

An, D., Danhorn, T., Fuqua, C., and Parsek, M. R. (2006). Quorum sensing and motility mediate interactions between Pseudomonas aeruginosa and Agrobacterium tumefaciens in biofilm cocultures. Proc. Natl. Acad. Sci. U. S. A. 103, 3828-3833. doi: 10.1073/pnas.0511323103

Andrade, N. J., AJao, D. B., and Zottola, E. A. (1998). Growth and adherence on stainless steel by Enterococcus faecium cells. J. Food Prot. 61, 1454-1458. doi: 10.4315/0362-028x-61.11.1454

Astm International, (2019). Standard Specification for Seamless and Welded Austenitic and Ferritic/Austenitic Stainless Steel Sanitary Tubing 1. West Conshohocken, PA: ASTM International.

Bartel, L. C., Abrahamovich, E., Mori, C., López, A. C., and Alippi, A. M. (2018). Bacillus and Brevibacillus strains as potential antagonists of Paenibacillus larvae and Ascosphaera apis. J. Apic. Res 58, 117-132. doi: 10.1080/00218839.2018. 1495439

Bizani, D., Motta, A. S., Morrissy, J. A. C., Terra, R. M. S., Souto, A. A., and Brandelli, A. (2005). Antibacterial activity of cerein $8 \mathrm{~A}$, a bacteriocin-like peptide produced by Bacillus cereus. Int. Microbiol. 8, 125-131.

Bos, R., Mei, H. C., Gold, J., and Busscher, H. J. (2000). Retention of bacteria on a substratum surface with micro-patterned hydrophobicity. FEMS Microbiol. Lett. 189, 311-315. doi: 10.1111/j.1574-6968.2000.tb09249.x

Bremer, P. J., Monk, I., and Osborne, C. M. (2001). Survival of Listeria monocytogenes attached to stainless steel surfaces in the presence or absence of Flavobacterium spp. J. Food Prot. 64, 1369-1376. doi: 10.4315/0362-028x64.9.1369

Collazo, C., Noguera, V., Aguiló-Aguayo, I., Abadias, M., Colás-Medà, P., Nicolau, I., et al. (2019). Assessing water-assisted UV-C light and its combination with peroxyacetic acid and Pseudomonas graminis CPA-7 for the inactivation and inhibition of Listeria monocytogenes and Salmonella enterica in freshcut 'Iceberg' lettuce and. Int. J. Food Microbiol. 297, 11-20. doi: 10.1016/J. IJFOODMICRO.2019.02.024

Doijad, S. P., Barbuddhe, S. B., Garg, S., Poharkar, K. V., Kalorey, D. R., Kurkure, N. V., et al. (2015). Biofilm-forming abilities of Listeria monocytogenes serotypes isolated from different sources. PLoS One 10:e0137046. doi: 10.1371/journal. pone. 0137046

Douriet-Gámez, N. R., Maldonado-Mendoza, I. E., Ibarra-Laclette, E., Blom, J., and Calderón-Vázquez, C. L. (2018). Genomic analysis of Bacillus sp. Strain B25, a biocontrol agent of maize pathogen Fusarium verticillioides. Curr. Microbiol. 75, 247-255. doi: 10.1007/s00284-017-1372-1

Du, H., Yang, J., Lu, X., Lu, Z., Bie, X., Zhao, H., et al. (2018). Purification, characterization, and mode of action of plantaricin GZ1-27, a novel bacteriocin against Bacillus cereus. J. Agric. Food Chem. 66, 4716-4724. doi: 10.1021/acs. jafc.8b01124

Elias, S., and Banin, E. (2012). Multi-species biofilms: living with friendly neighbors. FEMS Microbiol. Rev. 36, 990-1004. doi: 10.1111/j.1574-6976.2012. 00325.x

Fayad, N., Kallassy Awad, M., and Mahillon, J. (2019). Diversity of Bacillus cereus sensu lato mobilome. BMC Genomics 20:436. doi: 10.1186/s12864-019-5764-4 scholarship. The authors thank the Laboratório Multiusuários (LAMULT) of Instituto de Física "Gleb Wataghin," UNICAMP, Campinas, Brazil.

\section{SUPPLEMENTARY MATERIAL}

The Supplementary Material for this article can be found online at: https://www.frontiersin.org/articles/10.3389/fmicb. 2020.00177/full\#supplementary-material

Fiedoruk, K., Drewnowska, J. M., Daniluk, T., Leszczynska, K., Iwaniuk, P., and Swiecicka, I. (2017). Ribosomal background of the Bacillus cereus group thermotypes. Sci. Rep. 7, 1-10. doi: 10.1038/srep46430

Fox, E. M., Solomon, K., Moore, J. E., Wall, P. G., and Fanning, S. (2014). Phylogenetic profiles of in-house microflora in drains at a food production facility: comparison and biocontrol implications of Listeria-positive andnegative bacterial populations. Appl. Environ. Microbiol. 80, 3369-3374. doi: 10.1128/AEM.00468-14

Friedlander, A., Nir, S., Reches, M., and Shemesh, M. (2019). Preventing biofilm formation by dairy-associated bacteria using peptide-coated surfaces. Front. Microbiol. 10:1405. doi: 10.3389/fmicb.2019.01405

Ganegama Arachchi, G. J., Cridge, A. G., Dias-Wanigasekera, B. M., Cruz, C. D., McIntyre, L., Liu, R., et al. (2013). Effectiveness of phages in the decontamination of Listeria monocytogenes adhered to clean stainless steel, stainless steel coated with fish protein, and as a biofilm. J. Ind. Microbiol. Biotechnol. 40, 1105-1116. doi: 10.1007/s10295-013-1313-3

Giaouris, E., Heir, E., Desvaux, M., Hébraud, M., Møretrø, T., Langsrud, S., et al. (2015). Intra- and inter-species interactions within biofilms of important foodborne bacterial pathogens. Front. Microbiol. 6:841. doi: 10.3389/fmicb. 2015.00841

Giovannacci, I., Ermel, G., Salvat, G., Vendeuvre, J. L., and Bellon-Fontaine, M. N. (2000). Physicochemical surface properties of five Listeria monocytogenes strains from a pork-processing environment in relation to serotypes, genotypes and growth temperature. J. Appl. Microbiol. 88, 992-1000. doi: 10.1046/j.13652672.2000.01057.x

Goff, H. D. (2019). "Dairy Product Processing Equipment," in Handbook of Farm, Dairy and Food Machinery Engineering, (Amsterdam: Elsevier), 245-265. doi: 10.1016/b978-0-12-814803-7.00011-7

Gutiérrez, D., Rodríguez-Rubio, L., Martínez, B., Rodríguez, A., and García, P. (2016). Bacteriophages as weapons against bacterial biofilms in the food industry. Front. Microbiol. 7:825. doi: 10.3389/fmicb.2016.0 0825

Habimana, O., Heir, E., Langsrud, S., Asli, A. W., and Møretrø, T. (2010). Enhanced surface colonization by Escherichia coli O157:H7 in biofilms formed by an Acinetobacter calcoaceticus isolate from meat-processing environments. Appl. Environ. Microbiol. 76, 4557-4559. doi: 10.1128/AEM.0270 7-09

Hagens, S., and Loessner, M. J. (2014). Phages of Listeria offer novel tools for diagnostics and biocontrol. Front. Microbiol. 5:159. doi: 10.3389/fmicb.2014. 00159

Haraguchi, Y., Goto, M., Kuda, T., Fukunaga, M., Shikano, A., Takahashi, H., et al. (2019). Inhibitory effect of Lactobacillus plantarum Tennozu-SU2 and Lactococcus lactis subsp. lactis BF1 on Salmonella Typhimurium and Listeria monocytogenes during and post fermentation of soymilk. LWT 102, 379-384. doi: 10.1016/J.LWT.2018.12.042

Herald, P. J., and Zottola, E. A. (1988). Attachment of Listeria monocytogenes to stainless steel surfaces at various temperatures and $\mathrm{pH}$ values. J. Food Sci. 53, 1549-1562. doi: 10.1111/j.1365-2621.1988.tb09321.x

Hoodt, S. K., and Zottola, E. A. (1997). Growth media and surface conditioning influence the adherence of Pseudomonas fragi, Salmonella typhimurium, and Listeria monocytogenes cells to stainless steel. J. Food Prot. 60, 1034-1037. doi: 10.4315/0362-028X-60.9.1034 
Jahid, I. K., Mizan, M. F. R., Myoung, J., and Ha, S.-D. (2019). Aeromonas hydrophila biofilm, exoprotease, and quorum sensing responses to cocultivation with diverse foodborne pathogens and food spoilage bacteria on crab surfaces. Biofouling 34, 1079-1092. doi: 10.1080/08927014.2018.1519069

Janissen, R., Murillo, D. M., Niza, B., Sahoo, P. K., Nobrega, M. M., Cesar, C. L., et al. (2015). Spatiotemporal distribution of different extracellular polymeric substances and filamentation mediate Xylella fastidiosa adhesion and biofilm formation. Sci. Rep. 5:9856. doi: 10.1038/srep09856

Kabuki, D. Y., Kuaye, A. Y., Wiedmann, M., and Boor, K. J. (2004). Molecular subtyping and tracking of Listeria monocytogenes in latin-style fresh-cheese processing plants. J. Dairy Sci. 87, 2803-2812. doi: 10.3168/jds.S0022-0302(04) 73408-6

Kalmokoff, M. L., Austin, J. W., Wan, X. D., Sanders, G., Banerjee, S., and Farber, J. M. (2001). Adsorption, attachment and biofilm formation among isolates of Listeria monocytogenes using model conditions. J. Appl. Microbiol. 91, 725-734. doi: 10.1046/j.1365-2672.2001.01419.x

Karthikeyan, R., Gunasekaran, P., and Rajendhran, J. (2015). Molecular serotyping and pathogenic potential of Listeria monocytogenes isolated from milk and milk products in Tamil Nadu. India. Foodborne Pathog. Dis. 12, 522-528. doi: 10.1089/fpd.2014.1872

Kim, S. W., Haendiges, J., Keller, E. N., Myers, R., Kim, A., Lombard, J. E., et al. (2018). Genetic diversity and virulence profiles of Listeria monocytogenes recovered from bulk tank milk, milk filters, and milking equipment from dairies in the United States (2002 to 2014). PLoS One 13:e0197053. doi: 10.1371/ journal.pone. 0197053

Kim, Y., Kim, H., Beuchat, L. R., and Ryu, J.-H. (2019). Inhibition of Listeria monocytogenes using biofilms of non-pathogenic soil bacteria (Streptomyces spp.) on stainless steel under desiccated condition. Food Microbiol. 79, 61-65. doi: 10.1016/J.FM.2018.11.007

Knight, G. (2015). "Biofilm Control in Dairy Manufacturing Plants," in Biofilms in the Dairy Industry, eds K. H. Teh, S. Flint, J. Brooks, and G. Knight, (Chichester: John Wiley \& Sons, Ltd), 229-251. doi: 10.1002/9781118876282.ch12

Leriche, V., Chassaing, D., and Carpentier, B. (1999). Behaviour of L. monocytogenes in an artificially made biofilm of a nisin-producing strain of Lactococcus lactis. Int. J. Food Microbiol. 51, 169-182. doi: 10.1016/s0168-1605(99)00128-2

Liu, W., Røder, H. L., Madsen, J. S., Bjarnsholt, T., Sørensen, S. J., and Burmølle, M. (2016). Interspecific bacterial interactions are reflected in multispecies biofilm spatial organization. Front. Microbiol. 7:1366. doi: 10.3389/fmicb.2016. 01366

Liu, W., Russel, J., Burmølle, M., Sørensen, S. J., and Madsen, J. S. (2018). Microscale intermixing: a requisite for stable and synergistic co-establishment in a four-species biofilm. ISME J. 12, 1940-1951. doi: 10.1038/s41396-018-0112-2

Liu, W., Russel, J., Røder, H. L., Madsen, J. S., Burmølle, M., and Sørensen, S. J. (2017). Low-abundant species facilitates specific spatial organization that promotes multispecies biofilm formation. Environ. Microbiol. 19, 2893-2905. doi: 10.1111/1462-2920.13816

Logan, N. A., and De Vos, P. (2015). "Bacillaceae," in Bergey's Manual of Systematics of Archaea and Bacteria. Chichester: John Wiley \& Sons, Ltd, 21-128.

Lou, Z., Song, X., Ying, H., Hongxin, W., and Yiming, L. (2013). Separation and enrichment of burdock leaf components and their inhibition activity on biofilm formation of E. coli. Food Control 32, 270-274. doi: 10.1016/J.FOODCONT. 2012.11.020

Ludwig, W., Schleifer, K.-H., and Whitman, W. B. (2015). "Listeriaceae' fam. nov," in Bergey's Manual of Systematics of Archaea and Bacteria . Chichester: John Wiley \& Sons, Ltd, 1-1. doi: 10.1002/9781118960608.fbm00113

Marchand, S., De Block, J., De Jonghe, V., Coorevits, A., Heyndrickx, M., and Herman, L. (2012). Biofilm formation in milk production and processing environments; influence on milk quality and safety. Compr. Rev. Food Sci. Food Saf. 11, 133-147. doi: 10.1111/j.1541-4337.2011.00183.x

Maury, M. M., Bracq-Dieye, H., Huang, L., Vales, G., Lavina, M., Thouvenot, P., et al. (2019). Hypervirulent Listeria monocytogenes clones' adaption to mammalian gut accounts for their association with dairy products. Nat. Commun. 10:2488. doi: 10.1038/s41467-019-10380-0

Møretrø, T., Fanebust, H., Fagerlund, A., and Langsrud, S. (2019). Whole room disinfection with hydrogen peroxide mist to control Listeria monocytogenes in food industry related environments. Int. J. Food Microbiol. 292, 118-125. doi: 10.1016/J.IJFOODMICRO.2018.12.015
Nadell, C. D., Drescher, K., and Foster, K. R. (2016). Spatial structure, cooperation and competition in biofilms. Nat. Rev. Microbiol. 14, 589-600. doi: 10.1038/ nrmicro.2016.84

Nascimento, M. S., Moreno, I., and Kuaye, A. Y. (2009). Determinação da compatibilidade de desenvolvimento de culturas bacteriocinogências e fermento lático. Ciência Tecnol. Aliment. 29, 165-170. doi: 10.1590/s010120612009000100025

Nielsen, A. T., Tolker-Nielsen, T., Barken, K. B., and Molin, S. (2000). Role of commensal relationships on the spatial structure of a surface-attached microbial consortium. Environ. Microbiol. 2, 59-68. doi: 10.1046/j.1462-2920.2000.000 84.x

Ouertani, A., Chaabouni, I., Mosbah, A., Long, J., Barakat, M., Mansuelle, P., et al. (2018). Two new secreted proteases generate a casein-derived antimicrobial peptide in Bacillus cereus food born isolate leading to bacterial competition in milk. Front. Microbiol. 9:1148. doi: 10.3389/fmicb.2018.01148

Palmer, J., Seale, B., and Flint, S. (2015). "Significance of bacterial attachment," in Biofilms in the Dairy Industry, eds K. H. Teh, S. H. Flint, J. Brooks, and G. Knight, (Chichester: John Wiley \& Sons, Ltd), 17-35. doi: 10.1002/ 9781118876282.ch2

Parijs, I., and Steenackers, H. P. (2018). Competitive inter-species interactions underlie the increased antimicrobial tolerance in multispecies brewery biofilms. ISME J. 128:2061. doi: 10.1038/s41396-018-0146-5

Parizzi, F. Q. S., Andrade, N. J., Silva, A. S., Soares, N. F. F., and Silva, E. A. M. (2004). Bacterial adherence to different inert surfaces evaluated by epifluorescence microscopy and plate count method. Brazilian Arch. Biol. Technol. 47, 77-83. doi: 10.1590/s1516-89132004000100011

Park-ji, E., Hussain, M. S., Wei, S., Kwon, M., and Oh, D. H. (2019). Genotypic and phenotypic characteristics of biofilm formation of emetic toxin producing Bacillus cereus strains. Food Control. 96, 527-534. doi: 10.1016/j.foodcont.2018. 10.008

Ripolles-Avila, C., Hascoët, A. S., Martínez-Suárez, J. V., Capita, R., and Rodríguez-Jerez, J. J. (2019). Evaluation of the microbiological contamination of food processing environments through implementing surface sensors in an iberian pork processing plant: an approach towards the control of Listeria monocytogenes. Food Control 99, 40-47. doi: 10.1016/J.FOODCONT.2018.1 2.013

Ronner, A. B., and Wong, A. C. L. (1993). Biofilm development and sanitizer inactivation of Listeria monocytogenes and Salmonella Typhimurium on stainless steel and buna-n rubber. J. Food Prot. 56, 750-758. doi: 10.4315/0362028X-56.9.750

Ryser, E. T., Marth, E. H., and Marth, E. H. (2007). "The Genus Listeria and Listeria monocytogenes: phylogenetic position, taxonomy, and identification," in Listeria, Listeriosis, and Food Safety, 2nd Edn, eds E. T. Ryer, and E. H. Marth, (New York, NY: Marcel Dekker), 1-20. doi: 10.1201/9781420015188.ch1

Saldivar, J. C., Davis, M. L., and Johnson, M. G. (2018). "Listeria monocytogenes adaptation and growth at low temperatures: mechanisms and implications for foodborne disease," in Food and Feed Safety Systems and Analysis, (Cambridge, MA: Academic Press), 227-248. doi: 10.1016/b978-0-12-811835-1.000 13-0

Sallen, B., Rajoharison, A., Desvarenne, S., Quinn, F., and Mabilat, C. (1996). Comparative analysis of $16 \mathrm{~S}$ and $23 \mathrm{~S}$ rRNA sequences of Listeria species. Int. J. Syst. Bacteriol. 46, 669-674. doi: 10.1099/00207713-46-3-669

Saraoui, T., Fall, P. A., Leroi, F., Antignac, J. P., Chéreau, S., and Pilet, M. F. (2016). Inhibition mechanism of Listeria monocytogenes by a bioprotective bacteria Lactococcus piscium CNCM I-4031. Food Microbiol. 53, 70-78. doi: 10.1016/j. fm.2015.01.002

Sasahara, K. C., and Zottola, E. A. (1993). Biofilm formation by Listeria monocytogenes utilizes a primary colonizing microorganism in flowing systems. J. Food Prot. 56, 1022-1028. doi: 10.4315/0362-028X-56.12.1022

Saxena, P., Joshi, Y., Rawat, K., and Bisht, R. (2019). Biofilms: architecture, resistance, quorum sensing and control mechanisms. Indian J. Microbiol. 59, 3-12. doi: 10.1007/s12088-018-0757-6

Silva, H. O., Lima, J. A. S., Aguilar, C. E. G., Rossi, G. A. M., Mathias, L. A., and Vidal, A. M. C. (2018). Efficiency of different disinfectants on Bacillus cereus sensu stricto biofilms on stainless-steel surfaces in contact with milk. Front. Microbiol. 9:2934. doi: 10.3389/fmicb.2018.02934

Skowron, K., Wiktorczyk, N., Grudlewska, K., Kwiecińska-Piróg, J., WałeckaZacharska, E., Paluszak, Z., et al. (2019). Drug-susceptibility, biofilm-forming 
ability and biofilm survival on stainless steel of Listeria spp. strains isolated from cheese. Int. J. Food Microbiol. 296, 75-82. doi: 10.1016/J.IJFOODMICRO.2019. 02.021

Spanu, C. (2016). "Sporeforming bacterial pathogens in ready-to-eat dairy products," in Food Hygiene and Toxicology in Ready-to-Eat Foods, ed. P. Kotzekidou, (Cambridge, MA: Academic Press), 259-273. doi: 10.1016/b9780-12-801916-0.00015-7

Wang, N., Wang, L., Zhu, K., Hou, S., Chen, L., Mi, D., et al. (2019). Plant root exudates are involved in Bacillus cereus AR156 mediated biocontrol against Ralstonia solanacearum. Front. Microbiol. 10:98. doi: 10.3389/fmicb.2019.00098

Wayah, S. B., and Philip, K. (2018). Pentocin MQ1: a novel, broad-spectrum, pore-forming bacteriocin from Lactobacillus pentosus CS2 with quorum sensing regulatory mechanism and biopreservative potential. Front. Microbiol. 9:564. doi: $10.3389 /$ fmicb. 2018.00564

Wijman, J. G. E., De Leeuw, P. P. L. A., Moezelaar, R., Zwietering, M. H., and Abee, T. (2007). Air-liquid interface biofilms of Bacillus cereus: formation, sporulation, and dispersion. Appl. Environ. Microbiol. 73, 1481-1488. doi: 10. 1128/AEM.01781-06

Yuan, L., Hansen, M. F., Røder, H. L., Wang, N., Burmølle, M., and He, G. (2019). Mixed-species biofilms in the food industry: current knowledge and novel control strategies. Crit. Rev. Food Sci. Nutr. 1-17. doi: 10.1080/10408398.2019. 1632790
Yusra, F. A., and Novelina, P. (2014). Characterization of antimicrobial bacteriocin produced by Bacillus cereus SS28 isolates from budu, a traditionally fermented fish product of west Sumatera. Microbiol. Indones 8, 24-32. doi: 10.5454/mi. 8.1 .4

Zhao, T., Doyle, M. P., and Zhao, P. (2004). Control of Listeria monocytogenes in a biofilm by competitive-exclusion microorganisms. Appl. Environ. Microbiol. 70, 3996-4003. doi: 10.1128/AEM.70.7.3996-4003.2004

Zhao, T., Podtburg, T. C., Zhao, P., Schmidt, B. E., Baker, D. A., Cords, B., et al. (2006). Control of Listeria spp. by competitive-exclusion bacteria in floor drains of a poultry processing plant. Appl. Environ. Microbiol. 72, 3314-3320. doi: 10.1128/AEM.72.5.3314-3320.2006

Conflict of Interest: The authors declare that the research was conducted in the absence of any commercial or financial relationships that could be construed as a potential conflict of interest.

Copyright (c) 2020 Alonso, Harada and Kabuki. This is an open-access article distributed under the terms of the Creative Commons Attribution License (CC BY). The use, distribution or reproduction in other forums is permitted, provided the original author(s) and the copyright owner(s) are credited and that the original publication in this journal is cited, in accordance with accepted academic practice. No use, distribution or reproduction is permitted which does not comply with these terms. 